\title{
GONORRHOEA AND PENICILLIN \\ IS A SIX MONTHS' SURVEILLANCE \\ PERIOD NECESSARY?
}

BY

\author{
W. V. MACFARLANE \\ Physician in Charge, Venereal Diseases Department, Newcastle General Hospital, \\ Newcastle upon Tyne
}

In March, 1945, the Ministry of Health recommended that in gonorrhoea, tests of cure should be as set out in the Ministry memorandum, V21 (revised), and that blood tests for syphilis should be spaced over a period of at least six months. This precaution was apparently justified by the observations of Shafer and Zakon (1944) among others, that penicillin administration in gonorrhoea was liable to mask or delay the onset of concomitantly-acquired syphilitic infection. In this department the six-months' observation period was introduced in June, 1945, but was reduced to four months in July, 1948, because it was felt that the additional two-months' surveillance was not necessary. Further doubt, on the need for a surveillance period exceeding three months, led to the analysis of 2,600 gonococcal infections in 1,828 males and 772 females who attended this department between June, 1945, and February, 1949.

The five-injection method at 2-hourly intervals was introduced in May, 1945, and was replaced in February, 1946, by the single ethyl oleate injection of 0.2 m.u. penicillin; this in turn gave way to penicillin oil-wax suspension of which each patient received $0.3 \mathrm{~m} . \mathrm{u}$. penicillin in $1 \mathrm{ml}$. of the preparation; a similar dosage was maintained when the aqueous crystalline product was given to 164 male patients and also when the penicillin aluminium stearate and procaine penicillin preparations were used (see Table I).

\section{Outcome of Treatment}

All 49 infections which failed to respond to initial treatment occurred in males, the multiple aqueous penicillin schedule accounting for 23, ethyl-oleate for seventeen, and penicillin oil-wax for nine. Relapses noted after these three schedules of treatment numbered twelve, 34, and seventeen respectively. To these may be added two others which were treated with the single aqueous crystalline schedule.

The criterion of initial failure was a positive smear 24 to 48 hours after penicillin administration. Relapse was assumed when, after initial clinical and bacteriological success following penicillin treatment, gonococci re-appeared in smears taken during the ensuing 14 days.

Relapses and reinfections were difficult to distinguish ; for example, the majority of males who accounted for $89 \cdot 2$ per cent. of alleged "relapses", admitted alcoholic indulgence, some even to excess. On further questioning, this statement was occasionally amplified by an admission of possible exposure to infection-a circumstance which led us to cast doubt upon the denial of the others.

Dual Infections.-These were noted in 77 patients, 26 of whom were already under treatment for syphilis when they acquired gonorrhoea. Fifteen of the remainder, hitherto untreated, reported with both contagious syphilis and gonorrhoea but their

TABLE I

PENICILLIN PREPARATIONS EMPLOYED

\begin{tabular}{l|c|c|c|c|c|c}
\hline Patients & $\begin{array}{c}\text { Aqueous } \\
(30,000 \times 5 \times 2 \text {-hourly })\end{array}$ & $\begin{array}{c}\text { Ethyl } \\
\text { oleate }\end{array}$ & $\begin{array}{c}\text { Penicillin } \\
\text { oil-wax }\end{array}$ & $\begin{array}{c}\text { Aqueous } \\
(0 \cdot 3 \text { m.u. })\end{array}$ & $\begin{array}{c}\text { Aluminium j } \\
\text { stearate }\end{array}$ & $\begin{array}{c}\text { Procaine } \\
\text { penicillin }\end{array}$ \\
\hline $\begin{array}{c}\text { Male } \ldots \\
\text { Female .. }\end{array}$ & 353 & 248 & 1,019 & 164 & 31 & 13 \\
\hline Total .. & 564 & 162 & 399 & - & - & - \\
\hline
\end{tabular}


case histories suggested that those infections were not concomitantly acquired. Twenty men and fifteen women probably had acquired their infections simultaneously and in none was there any deviation from the normal incubation period of syphilis. In one man, however, the disease presented some unusual features:

Case M.217\%1.-Reported on January 26, 1946 with an uncomplicated gonorrhoea for which he received 0.15 m.u. (multiple injections) penicillin. Before completing his surveillance period he re-registered on May 30, 1946 with a fresh gonococcal infection for which he was treated with 0.2 m.u. penicillin oil-wax ; this treatment was again repeated for a third infection when he attended on July 8, 1946. The sources of all three infections were different women, each of whom was examined and treated for gonorrhoea. Between January and September no clinical or serological abnormalities indicative of syphilis was detected in this man but the blood Wassermann test on September 10, 1946 was reported to be strongly positive. (During those months blood Wassermann examinations had been performed at intervals not exceeding four weeks.) As a result of this test he was asked to report immediately but failed to do so. When examined on October 2, 1946 he showed a diffuse maculo-papular rash, seborrhoeic papules on the face, and ano-genital condylomata lata. While there is no proof that the two infections were concomitantly acquired, the delayed onset of clinical and serological evidence of syphilis may have been due to penicillin administration as an anti-gonorrhoeal measure, for it is difficult otherwise to explain persistently negative serological tests preceding the clinical appearance of well-established secondary syphilis.

Complications.-The possibility of complications having a bearing upon the duration of the surveillance period must now be examined.
Pre-Penicillin, (i.e. Initial) Complications.-Three per cent. of all the patients under review showed gonococcal complications at their initial visit, the incidence being higher amongst males (3.8 per cent.) than females ( 1.3 per cent.). Although they presented some complications when reporting their illness, all save one passed the test of cure 12 weeks from the time of penicillin administration. The exception was a male with gonococcal arthritis which proved refractory and fully 100 days elapsed before he could be regarded as cured. Thirty-nine per cent. acknowledged a previous gonococcal infection but in eight of those who reported initially with arthritis, there was no such history.

TABLE II

INCIDENCE OF COMPLICATIONS

\begin{tabular}{|c|c|c|c|c|c|}
\hline \multicolumn{4}{|c|}{ Nature of Complication } & No. & $\%$ \\
\hline Epididymitis & . & & & 46 & $2 \cdot 5$ \\
\hline Arthritis .. & .. & . . & . & 11 & $0 \cdot 6$ \\
\hline Prostatitis .. & & . & . & 7 & $0 \cdot 4$ \\
\hline Peri-urethral a & ess & . & . & 1 & 0.05 \\
\hline Proctitis $\quad \therefore$ : & & . & . & 1 & 0.05 \\
\hline Urethral follic & & . & . & 1 & 0.05 \\
\hline Tysonitis $\quad .$. & $\cdots$ & . & . & 1 & 0.05 \\
\hline Plantar fasciit & . & . & .. & 1 & 0.05 \\
\hline Conjunctivitis & $\cdots$ & .. & $\cdots$ & 1 & $0 \cdot 1$ \\
\hline Bartholinian & ess & $\cdot$ & $\ldots$ & 5 & $0 \cdot 6$ \\
\hline Salpingitis . . & $\cdots$ & ${ }^{\circ}$ & $\ldots$ & 3 & 0.4 \\
\hline Ophthalmia & $\cdots$ & . & .. & 1 & $0 \cdot 1$ \\
\hline
\end{tabular}

* Occurred in a female patient.

$\dagger$ In a female aged 59 years suffering from acute gonorrhoea.

Prior to the introduction of penicillin in the treatment of gonorrhoea, the duration of treatment and surveillance was determined by the presence (or otherwise) of complications at the initial visit

TABLE III

THE INFLUENCE OF VARIOUS MODES OF THERAPY ON THE INCIDENCE OF COMPLICATIONS SUBSEQUENT TO THE FIRST VISIT

\begin{tabular}{|c|c|c|c|c|c|c|c|}
\hline \multirow{2}{*}{\multicolumn{2}{|c|}{$\begin{array}{c}\text { Nature of } \\
\text { Complication }\end{array}$}} & \multicolumn{2}{|c|}{$\begin{array}{l}\text { Pre-sulphonamide Era } \\
(550)\end{array}$} & \multicolumn{2}{|c|}{$\begin{array}{l}\text { Sulphonamide Era } \\
(700)\end{array}$} & \multicolumn{2}{|c|}{$\begin{array}{l}\text { Penicillin Era } \\
(2,600)\end{array}$} \\
\hline & & (Male : 300. & Female : 250) & (Male : 500. & Female : 200) & (Male : 1,828. & Female : 772) \\
\hline 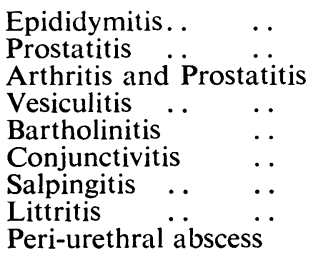 & $\begin{array}{l}\cdots \\
\cdots \\
\cdots \\
\cdots \\
\cdots \\
\cdots \\
\cdots\end{array}$ & $\begin{array}{r}16 \cdot 6 \\
24 \\
1 \cdot 3 \\
13 \cdot 6 \\
0 \cdot 5 \\
0 \cdot 7 \\
1 \cdot 2 \\
7 \cdot 3 \\
1 \cdot 2\end{array}$ & $\begin{array}{r}50 \\
72 \\
4 \\
41 \\
3 \\
4 \\
3 \\
22 \\
3\end{array}$ & $\begin{array}{l}5 \cdot 7 \\
5 \\
0 \cdot 4 \\
2 \cdot 2 \\
0 \cdot 4 \\
0 \cdot 14 \\
1 \\
0 \cdot 4 \\
0 \cdot 4\end{array}$ & $\begin{array}{r}11 \\
25 \\
2 \\
11 \\
3 \\
1 \\
2 \\
2 \\
2\end{array}$ & $\begin{array}{l}0 \cdot 8 \\
0 \cdot 5 \\
0 \cdot 3 \\
0 \cdot 1 \\
0 \cdot 05 \\
0.05 \\
0 \cdot 05 \\
- \\
-\end{array}$ & $\begin{array}{r}14 \\
9 \\
5 \\
2 \\
1 \\
1 \\
1 \\
-\end{array}$ \\
\hline Total & . & $36 \cdot 7$ & 202 & 8.43 & 59 & $1 \cdot 27$ & 33 \\
\hline
\end{tabular}


or their appearance subsequently. Men fortunate enough to have avoided complications were discharged as cured after 10 to 12 weeks, a period long enough to cover the maximum incubation period of syphilis which might have been concomitantly acquired. Females, however, were required to attend for at least 5 to 6 months.

Local therapy, essentially the main basis of treatment in the pre-sulphonamide era, was associated with the highest incidence (36.7 per cent.) of complications. Quite apart from a doubtful germicidal value, local therapy rather than gonococcal infection, was probably instrumental in causing many complications through indiscreet and overzealous application which produced chemical and mechanical trauma to the delicate tissues. This conclusion is supported by the marked reduction in the frequency of complications in the sulphonamide era $(8.43$ per cent.) when the cardinal therapeutic principles rested, if not entirely at least equally, on systemic as opposed to local measures. While the abandonment of local therapy in the penicillin era has doubtlessly played a part in minimizing complications, the remarkably low incidence (1.27 per cent.) can almost certainly be explained by the extreme sensitivity of the gonococcus to this rapidly acting antibiotic.

Complications during Treatment with Penicillin.These occurred in 33 cases ; fifteen were slight and of short duration while the remainder could be classified as of moderate severity and did not usually exceed 10 to 14 days duration. The average period between the penicillin treatment and the onset of the complication was 32.4 days, the minimum being two days and the maximum 78 days. Complications lasted on an average nine days while minimum and maximum periods were three and fifteen days respectively. All had developed by the 12 th week of surveillance and fully 50 per cent. by the 5 th week (see Table III).

It is held that the gonococcus was not instrumental in causing epididymitis in the majority of those who developed this complication subsequent to penicillin treatment since in those patients bacteriological and clinical success not only immediately followed penicillin therapy but was maintained over a varying period, usually weeks.

Default and Surveillance.-We must now assess the incidence of default in relation to the length of the period of surveillance (Table IV). During the investigation 200 patients were observed for three months, 1700 for six months and, more recently, 700 for four months. Subsequent to penicillin administration in uncomplicated gonorrhoea, patients were asked to report on three consecutive days, thereafter bi-weekly for one week followed by three consecutive weekly attendances, then fortnightly until the end of the 3rd month; where the surveillance period exceeded this time, subsequent monthly visits were regarded as adequate.

Analysis of phase B (i.e., six-months' surveillance) clearly shows that default peaks were to be expected in the first week and the second and third months of surveillance respectively. Default after the third month was roughly only one-sixth of the total. The remarkable chronological similarity in the default peaks noted in all three phases of the experiment during the first twelve weeks of observation would appear to indicate that maximum default may be expected during that time, after which the problem becomes a minor one.

Between June, 1945, and February, 1949, 2,985 letters and 1,308 effectual visits were necessary to persuade 1,333 initial defaulters to re-attend and complete tests of cure. As was to be expected, case-holding demanded the maximum effort from

TABle IV

DEFAULT INCIDENCE IN THE VARIOUS STAGES OF SURVEILLANCE

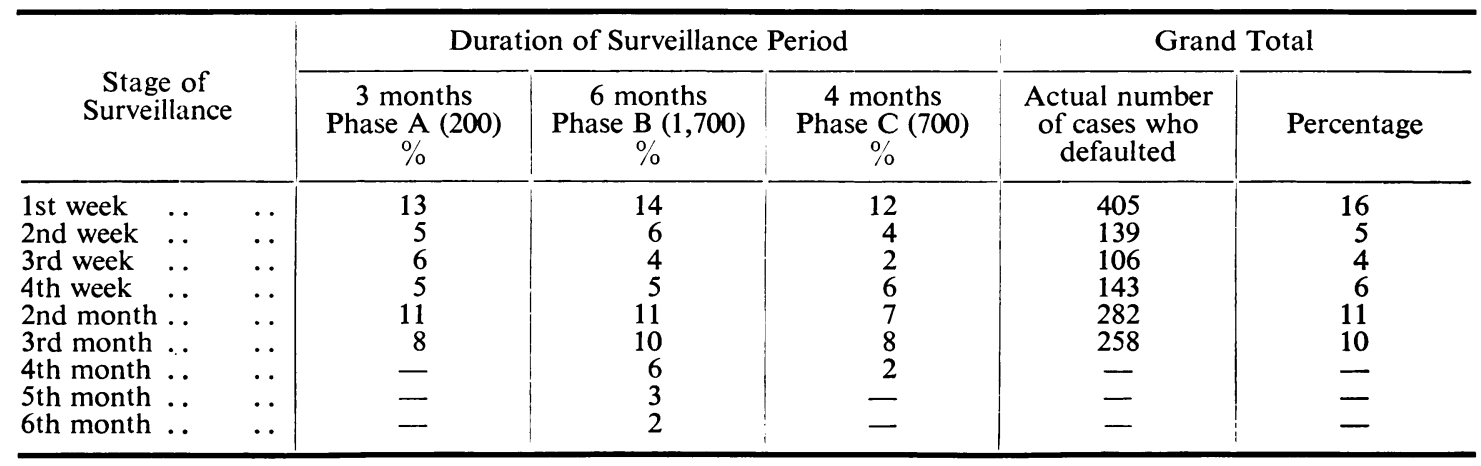


the Medico-Social Unit personnel around the default peaks, after which the problem offered no real difficulty.

\section{Summary and Conclusions}

2,600 case records of penicillin-treated gonorrhoeal infections have been examined with a view to determining whether the observation period should exceed three months.

The possibility of adequate penicillin dosage for gonorrhoea retarding the evolution of syphilis (especially if it has been concomitantly acquired), has been explored but in only one instance was this open to question.

A study of the complications developing before or after penicillin administration, fails to justify the extension of a twelve-weeks' surveillance period since all of them developed within that time.

Default during surveillance occurred mainly within the first three months, after which it caused no real anxiety to the medico-social unit personnel.

Further data supporting the three-months' observation period are :-

(a) As 61 per cent. of all females in this investigation were married and living with their husbands, it will be appreciated that domestic problems wellnigh prevented prolonged surveillance in many cases.

(b) A few patients of both sexes, on prolonged surveillance, became introspective.

Generally speaking, therefore, one concludes that a three-months' observation period is adequate for the vast majority of cases and that a longer period should not be established as a routine. Exceptions there must be however, such as the individual whose source of gonorrhoeal infection is known or suspected to have a contagious syphilis, and the sexually promiscuous who should be encouraged to attend for an indefinite period, a circumstance which perhaps would go a long way towards a reduction in the incidence of venereal diseases in the community.

Those presenting gonococcal complications at their initial visit would naturally be asked to attend until cured, irrespective of the twelve-weeks' surveillance period.

\section{REFERENCE}

Shafer, B., and Zakon, S. J. (1944). Arch. Derm. Syph., Chicago, 50, 200. 